\title{
IMAGINARIOS VISUALES EN TORNO A LO FEMENINO ${ }^{1}$
}

\section{Visual Imaginaries around the Feminine}

1 El título original del proyecto es «Imaginarios visuales en torno a lo femenino (1880-1916)». El proyecto de tesis fue aprobado en 2017.
Johanna Lezcano | johannalezcano@gmail.com

Facultad de Bellas Artes Universidad Nacional de La Plata

Argentina

Directora: Natalia Giglietti / nataliagiglietti@gmail.com Teoría de la historia. Facultad de Bellas Artes Universidad Nacional de La Plata. Argentina

Recibido: 13/2/2018 Aceptado: 21/5/2018

\section{RESUMEN}

A fines del siglo XIX y principios del XX, la Argentina vivió un proceso en donde las figuras de poder de todos los campos buscaron ubicarla como potencia mundial. En el plano cultural, se sentaron las bases del arte nacional. En este contexto determinadas obras de desnudo fueron visibilizadas y pasaron a la historia. Otras, apenas mencionadas, no han sido analizadas hasta el hoy. Mediante el análisis de los planos públicos y privados, dentro y fuera del campo artístico, se obtendrá una aproximación de los imaginarios visuales de la época.

\section{PALABRAS CLAVE}

Desnudo femenino; arte nacional argentino; imaginarios visuales

\section{ABSTRACT}

By the end of the XIX Century, Argentina was immersed in a process where the leading figures of all fields intended to position the country as a world power. At a cultural level the idea of a National Art was set ground. Was in this context that certain nude works were noticed and they made history. Other, were barely mentioned and haven't been analyzed until nowadays. Using the analysis of the public and private planes, inside and outside the artistic field, an approximation of the visual imaginaries of the time approaches.

\section{KEYWORDS}

Feminine nude; Argentine national art; visual imaginary 
Esta investigación reflexiona sobre los imaginarios femeninos que se construyeron hacia finales del siglo XIX y principios del XX en la Argentina. En esta época surgieron fuertemente ideas de progreso $y$ fantasías de un país devenido en potencia mundial tanto en el plano económico como en el cultural. En el arte, las personalidades del momento (Severo Rodríguez Etchart, Eduardo Sívori, Ernesto de la Cárcova, Augusto Ballerini, Graciano Mendilaharzu, Ángel Della Valle, Eduardo Schiaffino), reunidas en un grupo que luego se conoció como la generación del ochenta, lograron reconocimientos mundiales y establecieron los primeros grandes eventos nacionales: la creación de la Sociedad de Estímulo de Bellas Artes (1876), la creación del Ateneo donde se realizaron las primeras exposiciones de arte argentino (1893) y, finalmente, la concreción del Museo Nacional de Bellas Artes (MNBA) (1896).

Una de las formas de consagración para los artistas era viajar a Europa y posicionar su obra en algún salón. Poder representar un desnudo, considerado un género mayor (como el género histórico o el retrato), era otra de las vías de consagración. A su vez, las mujeres que decidieron dedicarse profesionalmente al arte pictórico también encontraron en el desnudo un espacio de visualización o, por lo menos, un intento de romper con los parámetros establecidos para una artista mujer.

Entonces comienzan nuestros interrogantes sobre cómo se construyó la imagen femenina en el momento en el que se sentaron las bases del arte nacional: ¿cuál fue el papel de las mujeres artistas en este contexto?, ¿cuáles fueron los parámetros desde los que se configuraron las bases del arte nacional y qué relación mantuvieron con la imagen de la mujer?, ¿por dónde circulaban las imágenes de desnudos hasta ese momento?, ¿solo pertenecían al ámbito de los salones?

El objetivo de la investigación es establecer y estudiar los imaginarios visuales en torno a lo femenino entre 1880 y 1916, analizando los aspectos formales, compositivos y contextuales de cada de una de las obras. En función de las preguntas realizadas se estudian producciones visuales en las cuales el protagonista es el cuerpo femenino desnudo. A su vez, cada imagen es seleccionada por encontrarse de alguna manera desplazada de los criterios canónicos del desnudo femenino. Dicho desplazamiento se observa en tres ejes: en torno al objeto producido, al sujeto productor y al modo de circulación.

En el primer eje se trabaja con producciones visuales en las que el cuerpo femenino no se adapta a los criterios formales y compositivos del género desnudo (cuerpo idealizado, formas simétricas, completamente redondeadas, tez blanca, senos pequeños y circulares, 
etcétera). El caso de mayor repercusión podría ser El despertar de la criada, de Eduardo Sívori, donde por primera vez un artista pintó a una mujer sin justificar su desnudez: no era ni una prostituta ni una figura mítica y, por sobre todas las cosas, no era una mujer de bellas proporciones (según los criterios de la época) ni pertenecía a un círculo social que justificara la necesidad de pintar su imagen. Lo interesante de observar en todas las obras hechas por artistas varones es que, pese a que fueron producciones que escaparon al canon formal, lograron gran repercusión y se sumaron a colecciones importantes como la del MNBA [Figuras 1 y 2 ].

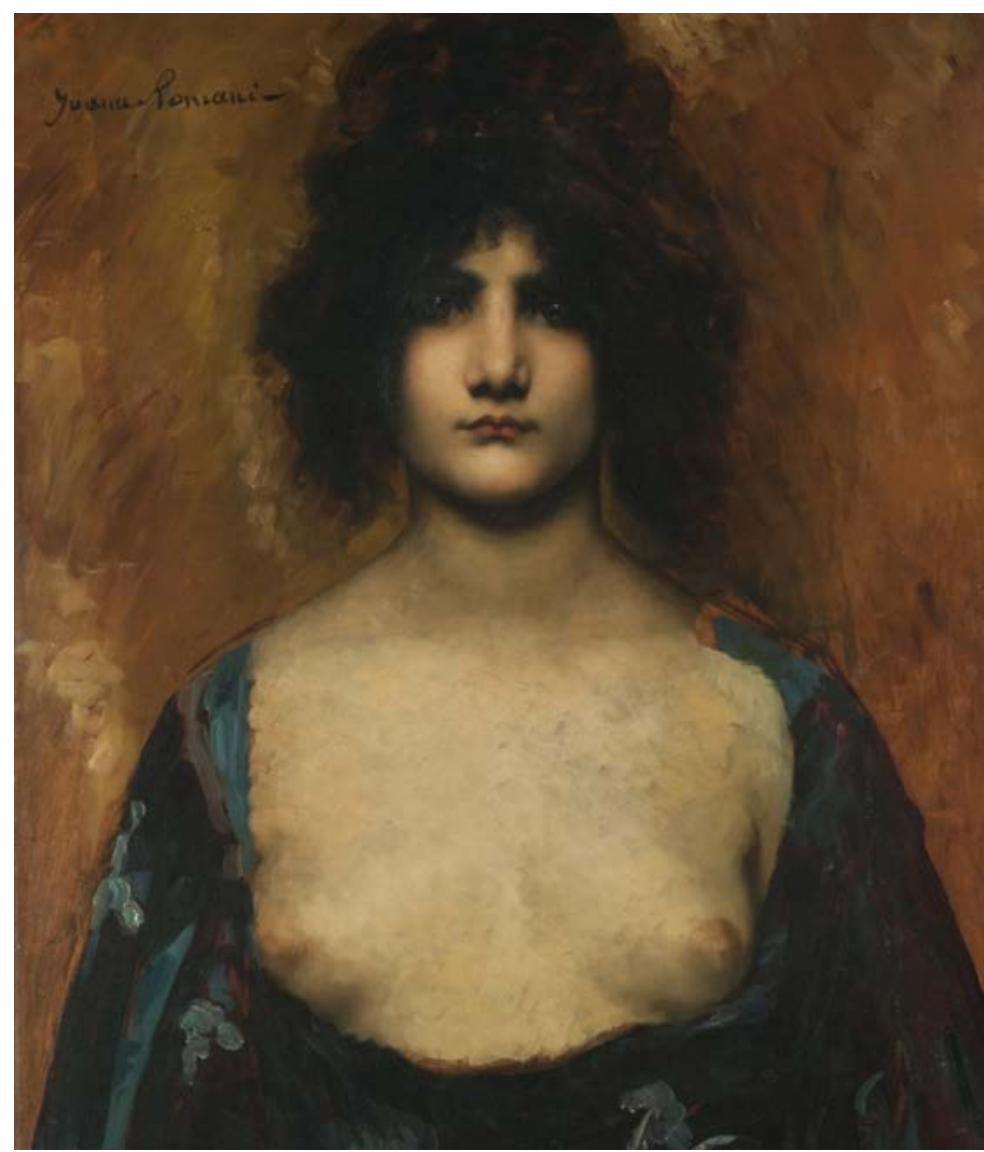

Figura 1. Joven orienta/ (s/f), Juana Romani. Óleo sobre tabla, 81 x 53, 5 cm. Incorporada al MNBA en 1910 por una donación

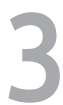




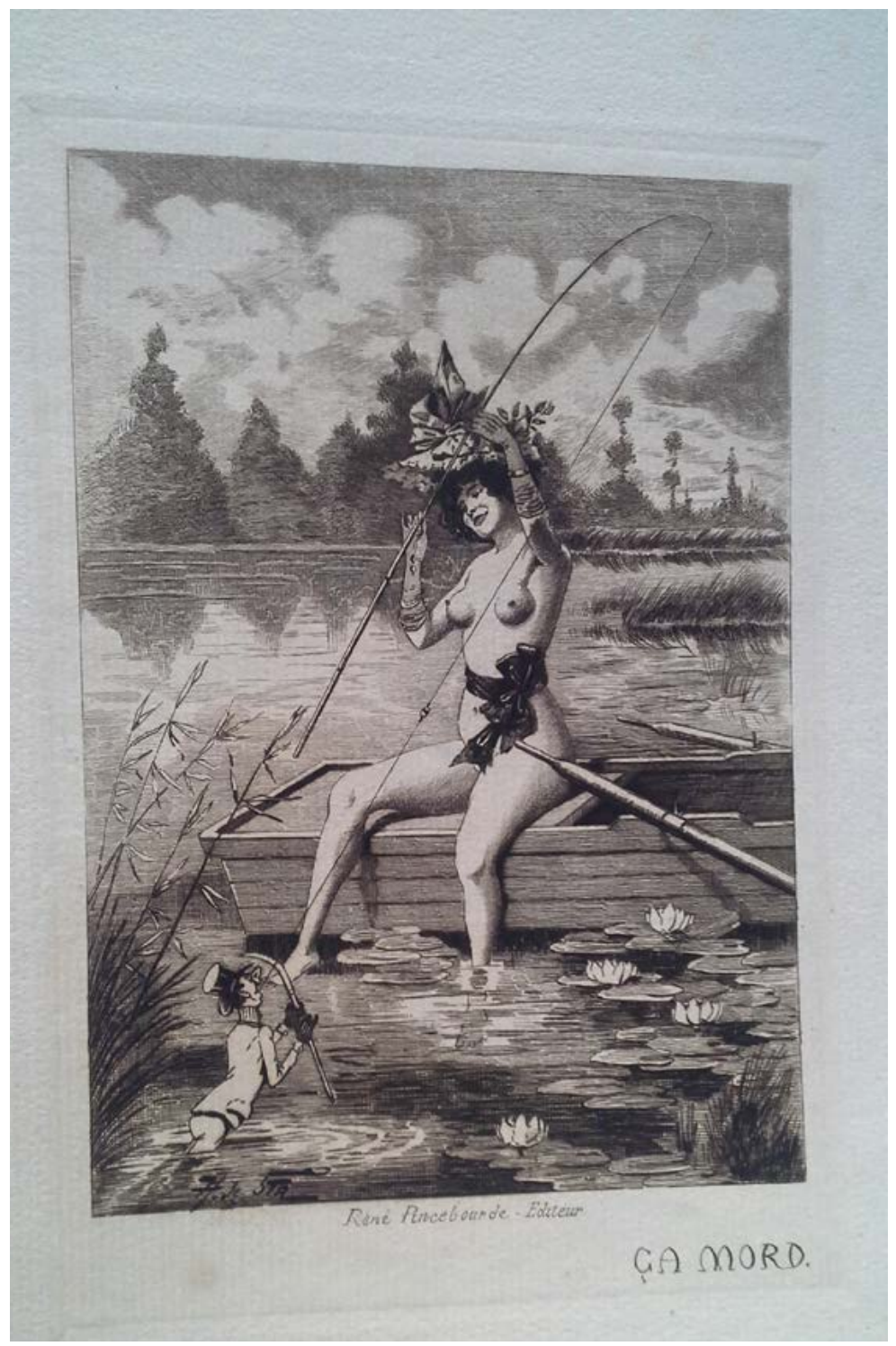

Figura 2. Pica (fechada entre 1846 y 1920), Henry De Sta. Litografía, 11,5 x 16, 5 cm. Perteneciente a la Biblioteca Nacional Mariano Moreno 
En el segundo eje hablamos de desplazamientos en torno al sujeto productor, ya que eran artistas mujeres que en ese momento eran una minoría dentro del campo artístico. Por ejemplo, Lía Correa Morales realizó un desnudo que respetaba los criterios de composición establecidos, logró un lugar en el Salón Nacional de Artes Plásticas en 1913 y, posteriormente, ingresó a la colección del MNBA. Sin embargo, desde entonces fueron muy pocas las veces que la obra estuvo en exposición en el museo. Las artistas buscaron realizar un trabajo profesional y no meramente recreativo, como estaba previsto para ellas en ese período. Las tres obras que analizamos, pertenecientes al MNBA y al Complejo Museográfico Provincial E. Udaondo, hoy no están exhibidas.

Por último, los desplazamientos en torno al modo de circulación de las producciones hacen referencia a obras que no ocuparon los espacios preferenciales dentro del circuito artístico. En este apartado se tomaron imágenes del periódico La ilustración argentina (1888) para analizar algunas de las representaciones sobre la mujer que aparecieron por fuera del campo artístico en producciones culturales de mayor alcance. Esto se complementó con la serie de grabados, pertenecientes a la colección privada de Pedro Denegri, fechada entre 1880 y 1900 y conocida por pertenecer a la Biblioteca Nacional Mariano Moreno. Estos grabados son de origen francés y hasta el momento no se sabe cómo llegaron a la Argentina ni qué círculo de personas pudo llegar a tener contacto con las imágenes. Las mujeres representadas, desnudas, se encuentran satirizadas ya sea por el título o por las acciones que están realizando. Así, el análisis de este apartado se centra en la búsqueda de diferencias y semejanzas entre las representaciones sobre la mujer en imágenes que tuvieron distintos modos de circulación, en este caso, el ámbito público dado por la revista y el privado dado por la colección.

La metodología parte del marco teórico de los estudios visuales y de la crítica feminista. Los primeros plantean que las producciones analizables son aquellas vinculadas con una experiencia sensible, sin importar que vengan del campo artístico o de los medios visuales de comunicación masiva (Marchan Fiz, 2005). La crítica feminista visibiliza la tarea de las mujeres a lo largo de la historia e indaga en el ocultamiento hecho por los hombres de toda manifestación femenina (Nochlin, 2001).

A partir de lo mencionado surgen dos nuevas categorías de análisis: lo reconocido y lo invisibilizado ¿Qué producciones se encuentran al alcance de la sociedad y cuáles no? Responder los interrogantes acerca de cómo construyen el imaginario femenino las obras que se visibilizan y las que no, nos brindará la posibilidad de tener una mirada 
más certera sobre un determinado momento de nuestra historia del arte, seguir visibilizando la producción de las mujeres artistas $y$, sobre todo, profundizar acerca de cómo las imágenes establecen conductas y pensamientos en cada época.

\section{REFERENCIAS}

Nochlin, L. (2001). ¿Por qué no han existido grandes artistas mujeres? En K. Cordero Reiman e I. Sáenz (Comps.). Crítica feminista en la teoría $e$ historia del arte. Recuperado de https://sentipensaresfem.files. wordpress.com/2016/09/cordero_saenzcomps_critica_feminista_en_ la_teoria_e_historia_del_arte2001.pdf

Marchan Fiz, S. (2005). Las artes ante la cultura visual. En Estudios Visuales. La epistemología de la visualidad en la era de la globalización (pp. 75-90). Madrid, España: Akal. 